\title{
Groundwater Nutrient Geochemical Transformations in Organic-Rich Coastal Sediment
}

\author{
AleXANDER F. LAMORE*, AlEXANDRA CHURCH, \\ CHRISTOPHER JOHN BARNES II AND NATASHA DIMOVA
}

Box 870338, Tuscaloosa, AL 35487

[*correspondence: aflamore@crimson.ua.edu]

[aichurch@crimson.ua.edu] [cbarnes@anchorqea.com]

[ntdimova@ua.edu]

Previous studies of groundwater nutrient dynamics in coastal Baldwin County, AL indicate that groundwater is contaminated with $\mathrm{NO}_{3}{ }^{-}$. However, recently a mass-balance of nutrient fluxes indicated that there are positive fluxes of reduced nitrogen species, $\mathrm{NH}_{4}{ }^{+}$and dissolved organic nitrogen (DON), while $\mathrm{NO}_{3}{ }^{-}$fluxes were negative. It was also found that there is an organic-rich coastal sediment layer through which groundwater percolates, suggesting that geochemical transformations within this organic-rich layer could be responsible for the observed nitrogen fluxes. The goal of this study is to examine the geochemical transformations occurring in these organic-rich shallow coastal sediments, as well as to identify the quantity and quality of carbon exported by groundwater discharging to Mobile Bay, AL. In a laboratorybased study, sediment cores containing the identified organicrich layer collected from the eastern shore of Mobile Bay, where waters are impacted by hypoxia, were incubated with $25 \mathrm{ppm}$ and $50 \mathrm{ppm} \mathrm{NO}_{3}{ }^{-}$solutions, natural groundwater, and ultra-pure carbon-free water (UPCFW) to evaluate how the sediment reacts to different nutrient compositions. Analyses of the coastal sediment were conducted to evaluate in-situ sediment conditions and examine the history of the site, to gain insight on the transformations occurring. Nutrient results do not show excess of $\mathrm{NH}_{4}{ }^{+}$in pore water incubations with increased $\mathrm{NO}_{3}{ }^{-}$loading, but higher $\mathrm{NH}_{4}{ }^{+}$was detected from UPCFW incubations. DON fluxes are most significant with the highest nitrate loading, and lowest in UPCFW incubations. $\mathrm{NO}_{3}{ }^{-}$levels in pore water after incubation are lower than the amounts added to the system, while $\mathrm{NO}_{2}{ }^{-}$is consistantly higher in the experiments with added $\mathrm{NO}_{3}{ }^{-}$. Total carbon is generally higher in incubations without added $\mathrm{NO}_{3}$; however, calculated remineralization of organic matter is slightly higher where $\mathrm{NO}_{3}{ }^{-}$is added. Higher $\mathrm{NH}_{4}{ }^{+}$in the absence of $\mathrm{NO}_{3}{ }^{-}$loading, as well as significant DON from incubations with added $\mathrm{NO}_{3}^{-}$ suggest that the sediment acts as a source of reduced nitrogen species. Furthermore, $\mathrm{NO}_{2}{ }^{-}$is high, while $\mathrm{NH}_{4}{ }^{+}$and total nitrogen are not, suggesting loss of nitrogen from the system as gaseous nitrogen species; therefore, denitrification seems to be the most common pathway for $\mathrm{NO}_{3}{ }^{-}$reduction. 